\title{
Evolutionary origin of disease and complexity: A nonequilibrium thermodynamic solution
}

\author{
Lauren Gerard Koch ${ }^{1 *}$ \\ Steven L. Britton ${ }^{2,3}$ \\ ${ }^{1}$ Department of Physiology \& Pharmacology, The University of Toledo, Toledo, OH \\ ${ }^{2}$ Department of Anesthesiology, University of Michigan, Ann Arbor, MI \\ ${ }^{3}$ Department of Molecular and Integrative Physiology, University of Michigan, Ann Arbor, MI \\ ${ }^{*}$ Corresponding Author: \\ Lauren Gerard Koch \\ Department of Physiology \& Pharmacology \\ The University of Toledo \\ Toledo, Ohio \\ Phone: 419.383.4520 \\ Fax: 419.383.2871 \\ Lauren.Koch2@utoledo.edu
}




\section{Abstract}

Our long-term goal was to develop realistic animal models of complex disease that are underwritten by fundamental principles. Along this path we noted a literature demonstrating that low exercise capacity is a stronger predictor of death relative to all other clinical conditions including diabetes and smoking. From this linkage we formulated the Energy Transfer Hypothesis (ETH): Variation in capacity for energy transfer is the central mechanistic determinant of the divide between disease and health. As an unbiased test of the ETH we reasoned that: divergent artificial selection of rats based on low and high intrinsic treadmill running capacity would yield contrasting models of capacity for energy transfer that also divide for disease risks. Thirty-five generations of selection produced Low Capacity Runners (LCR) and High Capacity Runners (HCR) that differ in running capacity by over 8 -fold. Selection failed to disprove the ETH: disease risks segregate in the LCR, and the HCR demonstrate resistance to disease. For mechanistic explanation of the ETH we postulate that evolution, life, and thus disease follow the same entropic path of the other atoms and molecules of the universe. That is, 1) all systems tend towards Maximal Entropy Production, 2) entropy can temporarily decrease locally and form order such as life, 3) life developed with a genome as a path for coding for replication of energy metabolism units, and 4) evolution selects, in a constantly changing environment, for features that enhance life's capacity for energy transfer. That is, Maximal Entropy Production is the driving force mediating evolution. Thus, for each species, consider that there is phenotypic variation for this capacity that underlies the divide between health and disease. One goal of this paper is to stimulate new cross-disciplinary tests of the ETH of disease.

\section{Statement of the problem}

In 1986 Koch and Britton speculated that commonly used animal models of complex disease were too simplistic to enable progress in understanding conditions such as diabetes, heart failure, or cancer. Our goal was to devise a useful animal model system to understand the divide between disease and health. As a heuristic we formulated four simplistic "rules" for the minimal features of an animal model of complex disease. We thought a useful model should: 1) harbor clinically relevant phenotype(s), 2) be polygenic and thus heritable, 3) be modulable by positive (exercise) and negative (high fat diet) health environments, and 4) be explained by fundamental scientific principles (1). From our new "rules-based" perspective we considered that the study of widely used animal models of disease might actually be moving us further from useful knowledge because of their artificiality. Widely used overly simplistic examples include: streptozotocin for diabetes mellitus, acute coronary artery ligation for heart failure, gene knock in/knock out to reveal "disease-related" phenotypes and, ethylnitrosourea (ENU) mutagenesis with screening for mutants with clinically-relevant phenotypes. It was clear to us that these approaches did not emulate the polygenic nature of complex diseases and that alternative paths were needed.

\section{Formulation of a hypothesis}

We had noted the emergence of a strong statistical association between low capacity for energy transfer and high risk for disease in the clinical literature that started about 30 years ago $(2,3)$ and that is now extensively confirmed in large-scale contemporary studies $(4,5)$. Indeed, it is widely accepted that low capacity for energy transfer is a larger risk factor for death relative to all other clinical conditions including diabetes, smoking, and coronary artery disease (5). From this linkage of complex disease risks with low capacity for energy transfer, we initiated the Energy Transfer Hypothesis (ETH): Variation in capacity for energy transfer is the central mechanistic determinant of the divide between disease and health (1). Our long-term association with quantitative geneticist John P. Rapp (6) led us to consider that artificial selective breeding could possibly be used as a tool for first test of the ETH. That is, as an unbiased test of the ETH we reasoned that: divergent (two-way) selection of rats based on low and high intrinsic treadmill running capacity would yield contrasting models of capacity for energy transfer that also divide for disease risks.

The strong clustering of morbidities with low physical fitness suggests common causality. While it is widely hypothesized that some aspect of mitochondrial dysfunction is the mediator of the disease-fitness connection, a general mechanistic explanation for this association has not been defined (7). From the beginning we realized the risk of addressing the writ large nature of the Energy Transfer Hypothesis and using selection as a tool. We could not tell if we were closer to Karl Popper ("a hypothesis must make predictions to be falsifiable") or Wolfgang Pauli (the hypothesis is "not even wrong") (https://en.wikipedia.org/wiki/Not_even_wrong).

\section{Long-term selection for energy transfer capacity}

By 1996 we had gathered enough resources to start selection for low and high intrinsic (i.e., untrained) running capacity. We consider this intrinsic because the rats were selected based upon running tests on each of just five consecutive days when 12 weeks old. The founder population was $168 \mathrm{~N} / \mathrm{NIH}$ genetically heterogeneous rats 
provided by Carl Hansen and Karen Spuhler (8). Selection for low and high capacity was based upon distance run to exhaustion on a motorized treadmill using a velocity-ramped running protocol. The starting velocity was $10 \mathrm{~m} / \mathrm{min}$ and was increased by $1 \mathrm{~m} /$ min every $2 \mathrm{~min}$ (slope was constant at $15^{\circ}$ ). We considered this protocol the "rat equivalent" of the Bruce Protocol used clinically (9). At each generation, within-family selection was practiced using 13 families for both the low and high lines. A rotational breeding paradigm maintained the coefficient of inbreeding at less than $1 \%$ per generation (10).

As expected, because we started with a genetically heterogeneous population (11), the rats responded to artificial selection. On average by generation 35 of selection (18 years) the lines differed by greater than 8fold for intrinsic maximal running distance (Figure 1). Selection progressed successfully for both lines; formal regression analysis of distance over generations yielded a $p<2.2 \times 10^{-16}$ (i.e., at the machine epsilon in language $\mathrm{r}$ ) in support of a non-zero slope for both lines. These results are reminiscent of the sustained responsiveness seen in other selectively bred lines. For example, selection for oil concentration in maize continues to increase for over 100 generations (12). The long-term response to selection suggests that the running trait is influenced by many interacting genes.

\section{Selection did not falsify the ETH.}

Disease risks segregated with selection for low capacity exercise and resistance to risks segregated with selection for high capacity exercise. Table 1 shows 12 of the major complex disease risks the LCR harbor relative to the HCR including advanced aging, diminished longevity, metabolic syndrome, and increased susceptibility to ventricular fibrillation. For environment, the LCR are quite susceptible to weight gain on a high fat diet and the HCR are resistant (13).

\section{A theoretical base}

In 1966 Francis Crick declared that: "The ultimate aim of the modern movement in biology is to explain all biology in terms of physics and chemistry”.

We took Crick's broad statement as motivation to originate an approach to understanding complex diseases that is: 1) a deeper extension of conventional molecular biologic reductionism, and 2) based upon principles from non-equilibrium thermodynamics and evolution. The central theme is that evolution, life, and thus disease follow the same entropic path of the other atoms and molecules of the universe.
We sought a path for explanation of the ETH at the mechanistic level. For this, we applied fundamental properties of matter by integrating ideas from Robert Endres (14), Hans Krebs (15), and Peter Mitchell (16). The ideas can be summarized in four statements: 1) Net entropy (S) is always increasing and systems tend towards Maximal Entropy Production (MEP). 2) Entropy can temporarily decrease locally and ordered systems can form (order from disorder) and these ordered systems can dissipate energy faster than non-ordered systems. 3) Among the many possible ordered systems, what we term life developed with a genome as a path for coding for replication of energy metabolism units. 4) Evolution selects, in a constantly changing environment, for features that enhance life's capacity for energy transfer. Thus, for each species, consider that there is phenotypic variation for this capacity that underlies the divide between health and disease (Figure 2). Our artificial selection outcome is consistent with these arguments.

\section{An Extension and meshing of new ideas}

Jonathon Pritchard and colleagues (17) re-evaluated the genetic contribution to complex traits and hypothesized that there is an extremely large number of causal variants with tiny (non-zero) effects on height and other complex traits. Moreover, these variants are spread widely across the genome, such that most $100-\mathrm{kb}$ windows contribute to variance in height. They refer to this hypothesis as an "omnigenic model" and estimate that more than 100,000 SNPs exert independent causal effects on height. This type of function is consistent with our above theoretical arguments. That is, the emergence of life represented pathways for enhanced energy transfer that utilized the entire genome for moment-to-moment infinitesimal adjustments to environment. Pritchard proposes that disease risk is driven by genes with no obvious connection to disease that is propagated through regulatory networks to a much smaller number of core genes with direct effects. In refinement, we propose that disease risk is driven by genes that mediate energy transfer capacity that is concealed by the miniscule scale of each accumulative genetic change that occurs with evolution.

\section{Addendum}

The central concept of natural selection is the evolutionary fitness of an organism. Fitness is an organism's ability to survive and reproduce, which determines the size of its genetic contribution to the next generation. In a large reductionist step we propose that operation of Maximal Entropy Production is the driving force underlying evolution in the sense that it provides the energy for survival and reproductive functions. Of course, at the next level down we do not have specific explanation for the operation of Maximal Entropy 
Production as is also true for the quantum properties of teleportation, superposition, and entanglement (18).

We trust this succinct perspective will suggest further expanded cross-disciplinary tests of the ETH of disease. While the outcome of artificial selection for differential capacity for energy transfer is consistent with the ETH, explicit tests are needed.

\section{Acknowledgements}

The LCR-HCR rat model system was supported by the Office of Research Infrastructure Programs/OD grant
ROD012098A (to LGK and SLB) from the National Institutes of Health. Contact LGK (Lauren.Koch2@UToledo.Edu) or SLB (brittons@umich.edu) for information on the LCR and HCR rats: these rat models are maintained as an international collaborative resource at the University of Toledo, Toledo, Ohio.

We are grateful to Peter Mitchell, Bruce Walsh, Jonathon Flint, Richard Mott, John Rapp, and James Watson for insights on the development of ideas presented here.

\section{Bibliography and References Cited}

1. Koch LG, Britton SL. Aerobic metabolism underlies complexity and capacity. J Physiol. 2008;586(1):83-95. Epub 2007/10/20. doi: jphysiol.2007.144709 [pii] 10.1113/jphysiol.2007.144709. PubMed PMID: 17947307; PMCID: 2375572.

2. Bonow RO, Borer JS, Rosing DR, Henry WL, Pearlman AS, McIntosh CL, Morrow AG, Epstein SE. Preoperative exercise capacity in symptomatic patients with aortic regurgitation as a predictor of postoperative left ventricular function and long-term prognosis. Circulation. 1980;62(6):1280-90. Epub 1980/12/01. PubMed PMID: 6777072.

3. Cooksey JD, Reilly P, Brown S, Bomze H, Cryer PE. Exercise training and plasma catecholamines in patients with ischemic heart disease. Am J Cardiol. 1978;42(3):372-6. Epub 1978/09/01. PubMed PMID: 685849.

4. Kokkinos P, Myers J, Kokkinos JP, Pittaras A, Narayan P, Manolis A, Karasik P, Greenberg M, Papademetriou V, Singh S. Exercise capacity and mortality in black and white men. Circulation.

2008;117(5):614-22. Epub 2008/01/24. doi: CIRCULATIONAHA.107.734764 [pii]

10.1161/CIRCULATIONAHA.107.734764. PubMed PMID: 18212278.

5. Myers J, Prakash M, Froelicher V, Do D, Partington S, Atwood JE. Exercise capacity and mortality among men referred for exercise testing. N Engl J Med. 2002;346(11):793-801. Epub 2002/03/15. doi:

10.1056/NEJMoa011858

346/11/793 [pii]. PubMed PMID: 11893790.

6. Rapp JP. Genetic analysis of inherited hypertension in the rat. Physiol Rev. 2000;80(1):135-72. Epub 2000/01/05. PubMed PMID: 10617767.

7. Koch LG, Britton SL. Theoretical and Biological Evaluation of the Link between Low Exercise Capacity and Disease Risk. Cold Spring Harbor perspectives in medicine. 2017. Epub 2017/04/09. doi: 10.1101/cshperspect.a029868. PubMed PMID: 28389512.

8. Hansen C, Spuhler K. Development of the National Institutes of Health genetically heterogeneous rat stock. Alcoholism, Clinical and Experimental Research. 1984;8(5):477-9.

9. Bruce RA, Blackmon JR, Jones JW, Strait G. EXERCISING TESTING IN ADULT NORMAL SUBJECTS AND CARDIAC PATIENTS. Pediatrics. 1963;32:SUPPL 742-56. Epub 1963/10/01. PubMed PMID: 14070531.

10. Koch LG, Britton SL. Artificial selection for intrinsic aerobic endurance running capacity in rats. Physiol Genomics. 2001;5(1):45-52. Epub 2001/02/13. doi: 5/1/45 [pii]. PubMed PMID: 11161005.

11. Falconer DS, Mackay TFC. Introduction to Quantitative Genetics. Essex: Addison Wesley Longman, Ltd.; 1996.

12. Dudley JW, Lambert RJ. 100 Generations of Selection for Oil and Protein in Corn. Plant Breeding Reviews: John Wiley \& Sons, Inc.; 2010. p. 79-110.

13. Novak CM, Escande C, Burghardt PR, Zhang M, Barbosa MT, Chini EN, Britton SL, Koch LG, Akil H, Levine JA. Spontaneous activity, economy of activity, and resistance to diet-induced obesity in rats bred for 
high intrinsic aerobic capacity. Horm Behav. 2010;58(3):355-67. doi: 10.1016/j.yhbeh.2010.03.013. PubMed PMID: WOS:000280933600002.

14. Endres RG. Entropy production selects nonequilibrium states in multistable systems. Scientific reports. 2017;7(1):14437. Epub 2017/11/02. doi: 10.1038/s41598-017-14485-8. PubMed PMID: 29089531; PMCID: PMC5663838.

15. Baldwin JE, Krebs H. The evolution of metabolic cycles. Nature. 1981;291(5814):381-2. Epub 1981/06/04. PubMed PMID: 7242661.

16. Mitchell P. Coupling of phosphorylation to electron and hydrogen transfer by a chemi-osmotic type of mechanism. Nature. 1961;191:144-8. Epub 1961/07/08. PubMed PMID: 13771349.

17. Boyle EA, Li YI, Pritchard JK. An Expanded View of Complex Traits: From Polygenic to Omnigenic. Cell. 2017;169(7):1177-86. doi: 10.1016/j.cell.2017.05.038. PubMed PMID: WOS:000403332400008.

18. Leibfried D, Knill E, Seidelin S, Britton J, Blakestad RB, Chiaverini J, Hume DB, Itano WM, Jost JD, Langer C, Ozeri R, Reichle R, Wineland DJ. Creation of a six-atom 'Schrodinger cat' state. Nature. 2005;438(7068):639-42. Epub 2005/12/02. doi: 10.1038/nature04251. PubMed PMID: 16319885.

19. Thompson HJ, Jones LW, Koch LG, Britton SL, Neil ES, McGinley JN. Inherent aerobic capacitydependent differences in breast carcinogenesis. Carcinogenesis. 2017;38(9):920-8. Epub 2017/09/16. doi: 10.1093/carcin/bgx066. PubMed PMID: 28911004.

20. Morris EM, Jackman MR, Johnson GC, Liu TW, Lopez JL, Kearney ML, Fletcher JA, Meers GM, Koch LG, Britton SL, Rector RS, Ibdah JA, MacLean PS, Thyfault JP. Intrinsic aerobic capacity impacts susceptibility to acute high-fat diet-induced hepatic steatosis. American journal of physiology Endocrinology and metabolism. 2014;307(4):E355-64. doi: 10.1152/ajpendo.00093.2014. PubMed PMID: 24961240; PMCID: 4137118.

21. Novak CM, Escande C, Burghardt PR, Zhang M, Barbosa MT, Chini EN, Britton SL, Koch LG, Akil H, Levine JA. Spontaneous activity, economy of activity, and resistance to diet-induced obesity in rats bred for high intrinsic aerobic capacity. Horm Behav. 2010;58(3):355-67. Epub 2010/03/31. doi: S0018-

506X(10)00068-1 [pii]

10.1016/j.yhbeh.2010.03.013. PubMed PMID: 20350549; PMCID: 2923555.

22. Seifert EL, Bastianelli M, Aguer C, Moffat C, Estey C, Koch LG, Britton SL, Harper ME. Intrinsic aerobic capacity correlates with inherent mitochondrial oxidative and $\mathrm{H} 2 \mathrm{O} 2$ emission capacities without major shifts in myosin heavy chain isoform. J Appl Physiol. 2012. Epub 2012/09/22. doi: japplphysiol.01475.2011 [pii]

10.1152/japplphysiol.01475.2011. PubMed PMID: 22995392.

23. Choi J, Chandrasekaran K, Demarest TG, Kristian T, Xu S, Vijaykumar K, Dsouza KG, Qi NR, Yarowsky PJ, Gallipoli R, Koch LG, Fiskum GM, Britton SL, Russell JW. Brain diabetic neurodegeneration segregates with low intrinsic aerobic capacity. Annals of Clinical and Translational Neurology. 2014;1(8):589604. doi: 10.1002/acn3.86.

24. Wikgren J, Mertikas GG, Raussi P, Tirkkonen R, Ayravainen L, Pelto-Huikko M, Koch LG, Britton SL, Kainulainen H. Selective breeding for endurance running capacity affects cognitive but not motor learning in rats. Physiol Behav. 2012;106(2):95-100. Epub 2012/01/31. doi: S0031-9384(12)00023-6 [pii]

10.1016/j.physbeh.2012.01.011. PubMed PMID: $22285210 ;$ PMCID: 3314147.

25. WISLOFF U, NAJJAR S, ELLINGSEN O, HARAM P, SWOAP S, AL-SHARE Q, FERNSTROM M, REZAEI K, LEE S, KOCH L, BRITTON S. Cardiovascular risk factors emerge after artificial selection for low aerobic capacity. Science. 2005;307(5708):418-20. doi: 10.1126/science.1108177. PubMed PMID: WOS:000226492300045.

26. He Y, Liu W, Koch LG, Britton SL, Keep RF, Xi G, Hua Y. Susceptibility to intracerebral hemorrhageinduced brain injury segregates with low aerobic capacity in rats. Neurobiology of disease. 2012. Epub

2012/09/04. doi: S0969-9961(12)00301-4 [pii]

10.1016/j.nbd.2012.08.014. PubMed PMID: 22939993.

27. Park SJ, Gavrilova O, Brown AL, Soto JE, Bremner S, Kim J, Xu X, Yang S, Um JH, Koch LG, Britton SL, Lieber RL, Philp A, Baar K, Kohama SG, Abel ED, Kim MK, Chung JH. DNA-PK Promotes the Mitochondrial, Metabolic, and Physical Decline that Occurs During Aging. Cell Metab. 2017;25(5):1135-46 e7. Epub 2017/05/04. doi: 10.1016/j.cmet.2017.04.008. PubMed PMID: 28467930. 
bioRxiv preprint doi: https://doi.org/10.1101/356493; this version posted June 29,2018 . The copyright holder for this preprint (which was not certified by peer review) is the author/funder, who has granted bioRxiv a license to display the preprint in perpetuity. It is made available under

28. Muncey A, Saulles A, Baghdoyan HA, Koch LG, Britton SL, Lydic R. Rats bred for low intrinsic aerobic running capacity exhibit decreased and more disrupted sleep compared to those bred for high intrinsic aerobic running capacity. Sleep. 2008;31:A27-A8. PubMed PMID: WOS:000255419000083.

29. Hoydal MA, Stolen TO, Johnsen AB, Alvez M, Catalucci D, Condorelli G, Koch LG, Britton SL, Smith GL, Wisloff U. Reduced aerobic capacity causes leaky ryanodine receptors that trigger arrhythmia in a rat strain artificially selected and bred for low aerobic running capacity. Acta physiologica. 2014;210(4):854-64. doi: 10.1111/apha.12238. PubMed PMID: 24444142; PMCID: 3980721.

30. Koch LG, Kemi OJ, Qi N, Leng SX, Bijma P, Gilligan LJ, Wilkinson JE, Wisloff H, Hoydal MA, Rolim N, Abadir PM, van Grevenhof EM, Smith GL, Burant CF, Ellingsen O, Britton SL, Wisloff U. Intrinsic Aerobic Capacity Sets a Divide for Aging and Longevity. Circulation Research. 2011;109(10):1162-U151. doi: Doi 10.1161/Circresaha.111.253807. PubMed PMID: WOS:000296417200011.

31. Ren Y-y, Overmyer KA, Qi NR, Treutelaar MK, Heckenkamp L, Kalahar M, Koch LG, Britton SL, Burant CF, Li JZ. Genetic Analysis of a Rat Model of Aerobic Capacity and Metabolic Fitness. Plos One. 2013;8(10). doi: 10.1371/journal.pone.0077588. PubMed PMID: WOS:000325819400128.

\begin{tabular}{|c|c|c|}
\hline \multicolumn{3}{|c|}{ Table 1. } \\
\hline Susceptibility to cancer (19) & Fatty liver disease (20) & Low physical activity (21) \\
\hline Decreased OXPHOS (22) & Alzheimer’s neurodegeneration (23) & $\downarrow$ Hippocampal neurogenesis (24) \\
\hline Metabolic syndrome (25) & $\uparrow$ Susceptibility to cerebral hemorrhage (26) & Mechanism of aging: DNApk (27) \\
\hline Disordered sleep (28) & $\uparrow$ Vulnerability to ventricular fibrillation (29) & Premature aging (30) \\
\hline
\end{tabular}


bioRxiv preprint doi: https://doi.org/10.1101/356493; this version posted June 29 2018. The copyright holder for this preprint (which was not certified by peer review) is the author/funder, who has granted bioRxiv a license to display the preprint in perpetuity. It is made available under aCC-BY-NC 4.0 International license.

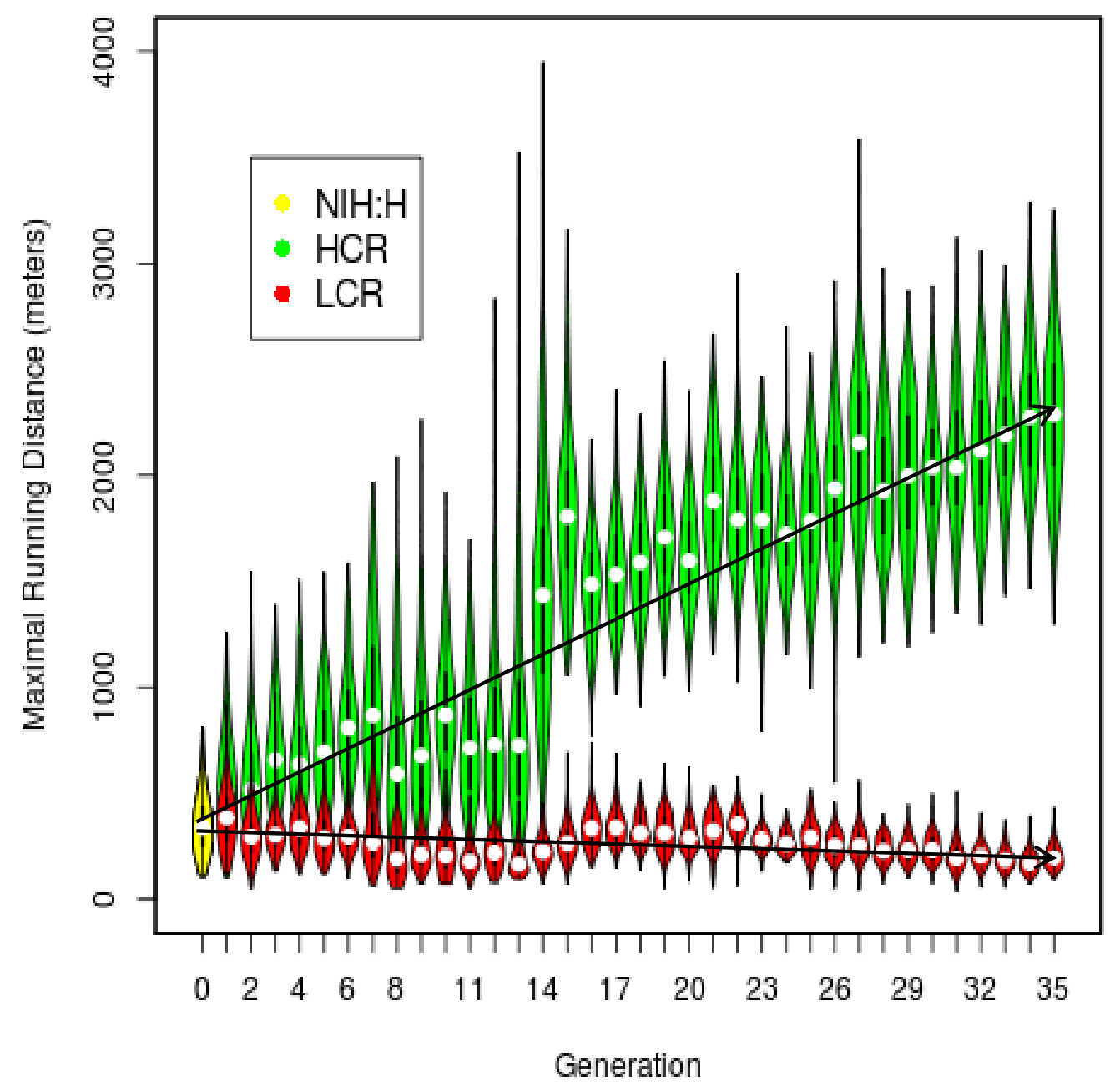

Figure 1. Response to selection for 35 generations. Each symbol represents the distribution of running distance for each generation in each line. The symbols for each generation combine box plots and kernel density plots to depict the observed probability density. Males and females combined ( $\mathrm{n}=13,886$ rats). NIH:H are the founder stock rats (31). 


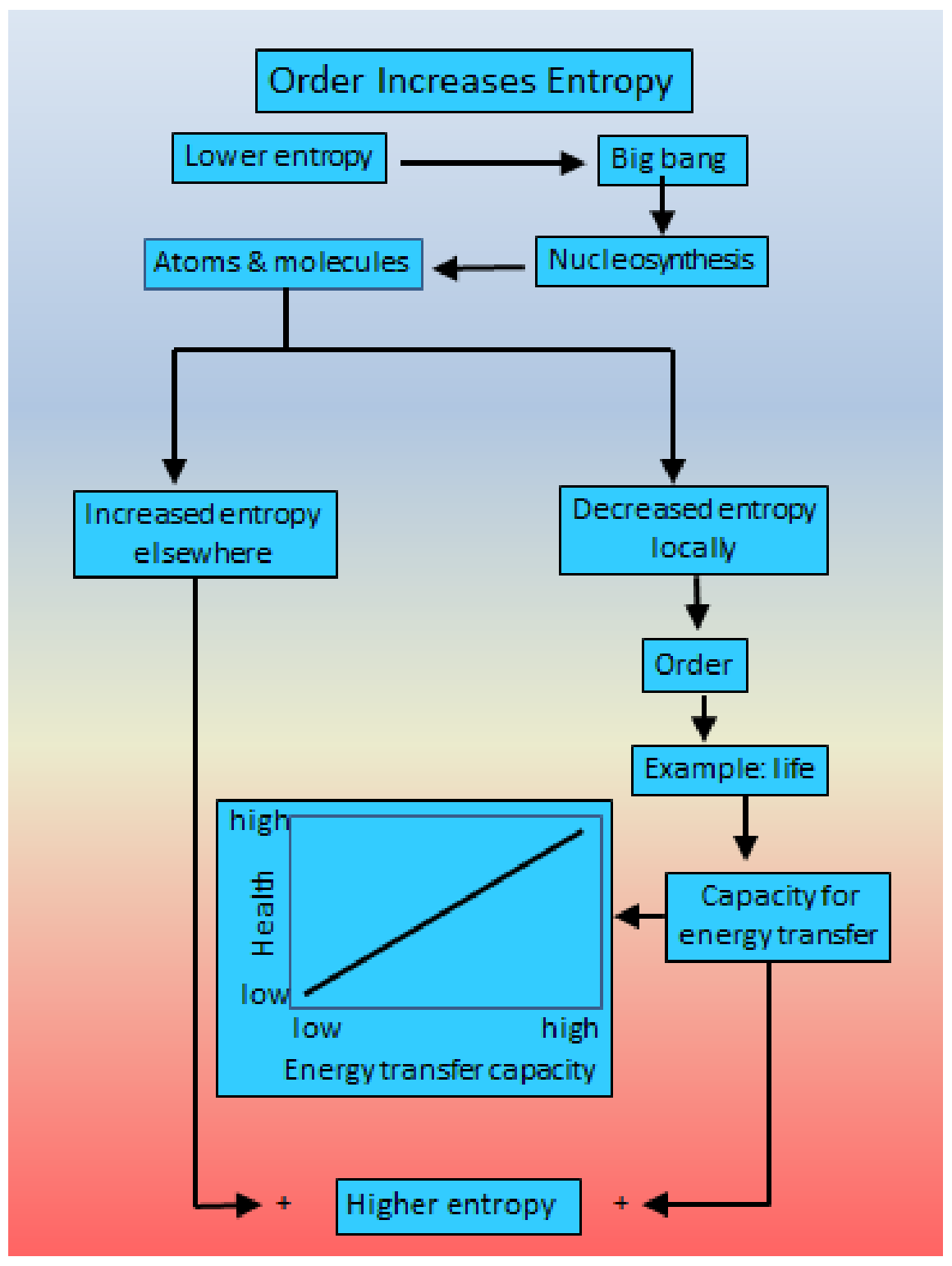

Figure 2. Time zero for biology can be considered as equivalent to the Big Bang and the subsequent formation of atoms (nucleosynthesis) that displayed the property of Maximal Entropy Production (MEP). Locally entropy can decrease (at the expense of increased entropy elsewhere) and ordered systems such as life can form. We postulate that attainment of MEP is the driving force underlying evolution. Thus, for each species, consider that there is phenotypic variation for this capacity that underlies mechanistically the association of low health with low capacity for energy transfer. 